\title{
Properties Tuning of Palm Kernel Shell Biochar Granular Activated Carbon Using Response Surface Methodology for Removal of Methylene Blue
}

\author{
S M Anisuzzaman ${ }^{\mathrm{a}, \mathrm{b}}$, Nirwana Sinring ${ }^{\mathrm{b}}$ and Rachel Fran Mansa ${ }^{\mathrm{b},{ }^{*}}$ \\ ${ }^{a}$ Energy Research Unit (ERU), Universiti Malaysia Sabah, 88400 Kota Kinabalu, Sabah, \\ Malaysia \\ ${ }^{b}$ Chemical Engineering Programme, Faculty of Engineering, Universiti Malaysia Sabah, \\ 88400 Kota Kinabalu, Sabah, Malaysia.
}

\begin{abstract}
This study aimed to produce palm kernel shell granular activated carbon (PKSGAC) from slow vacuum pyrolysed PKS biochar (PKSB) via chemical activation using a horizontal tubular split zone furnace. The study also investigated the effects of varying parameters of the PKSGAC on its colour removal ability. The PKSB was activated through chemical activation using potassium hydroxide (KOH) at various parameters such as activation temperature $\left(700^{\circ} \mathrm{C}\right.$ to $\left.850{ }^{\circ} \mathrm{C}\right), \mathrm{KOH}$ concentration $(50 \% \mathrm{w} / \mathrm{v}$ to $100 \% \mathrm{w} / \mathrm{v})$ and particle size of PKSB $(0.4 \mathrm{~mm}$ to $2.5 \mathrm{~mm})$. The novelty of this work lies in the study of chemical activation on various particle size ranges using response surface methodology (RSM) to model the relationships between various parameters. The PKSB was characterized to determine its thermal condition, and the PKSGAC was characterized to determine the iodine number, bulk density, ash content, moisture content, surface area and morphology structure. The parameters that were used for each sample were determined by using the RSM based on central composite design (CCD). In this study, design expert version 11.0 software was used and three parameters as independent variables were manipulated. Finally, three different PKSGAC samples of different particle sizes were used to test for the methylene blue $(M B)$ dye removal with the concentration of $5 \mathrm{mg} / \mathrm{l}, 10 \mathrm{mg} / \mathrm{l}, 15 \mathrm{mg} / \mathrm{l}$ and $20 \mathrm{mg} / \mathrm{l}$. Thermal analysis showed that the total weight loss of the PKSB sample was $58.30 \%$ and for PKSGAC the range of the product yield as shown from the RSM was from $33.23 \%$ to $96.33 \%$. The RSM also showed that the values for moisture content were in a range from $0 \%-39 \%$, as for the ash content value from $2 \%-12 \%$, while for the bulk density ranged from $0.17 \mathrm{~g} / \mathrm{cm}^{3}-0.50 \mathrm{~g} / \mathrm{cm}^{3}$. The highest iodine value achieved was $1320 \mathrm{mg} / \mathrm{g}$ at activation temperature of $850{ }^{\circ} \mathrm{C}, \mathrm{KOH}$ concentration of $50 \%$ $w / v$ and particle size of $0.4 \mathrm{~mm}$. From the RSM, an iodine number of $1100 \mathrm{mg} / \mathrm{g}$ could be obtained using an activation temperature of $850^{\circ} \mathrm{C}$, the $\mathrm{KOH}$ concentration of $69.22 \% \mathrm{w} / \mathrm{v}$ and the particle size of 0.59 $\mathrm{mm}$. From the BET analysis, the PKSGAC sample obtained $581 \mathrm{~m}^{2} / \mathrm{g}$ for $S_{B E T}$ and $0.3173 \mathrm{~cm}^{3} / \mathrm{g}$ for the $V_{\text {tot. }}$ The highest percentage dye removal of $M B$ dye was $89.61 \%$ to $97.63 \%$ at $775^{\circ} \mathrm{C}$ activation temperature, $75 \% \mathrm{w} / \mathrm{v} \mathrm{KOH}$ concentration and $0.4 \mathrm{~mm}$ particle size. This work produced RSM models to predict the relationships between the parameters and the response, as well as the performance on $M B$ dye removal.
\end{abstract}

Keywords: Activated carbon, Chemical activation, Palm kernel shell biochar, Potassium hydroxide, Pyrolysis.

* Corresponding author.
E-mail address: rfmansa@ums.edu.my

Manuscript History:

Received 21 September, 2021, Revised 8 October, 2021, Accepted 9 October, 2021, Published 31 October, 2021

Copyright (C) 2021 UNIMAS Publisher. This is an open access article under the CC BY-NC-SA 4.0 license.

https://doi.org/10.33736/jaspe.3961.2021

e-ISSN: 2289-7771

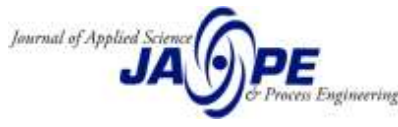




\section{Introduction}

Biochar has a lot of uses in agronomic and environmental applications which can either be produced by thermal decomposition of biomass under oxygen-limited conditions or by the pyrolysis process. The activation temperature during the pyrolysis process can affect the specific surface area, pore volume and biochar microspores. The choice ofprocess parameters depends on the desired product where fast pyrolysis produces a higher yield of bio-oil as compared to biochar while a vacuum and slow pyrolysis produce a higher yield of biochar [1]. Biochar can be activated into activated carbon (AC) through physical activation orchemical activation. Biochar undergoes partial gasification with activation agentssuch as steam or carbon dioxide. The gasification process is conducted at temperatures ranging from $700^{\circ} \mathrm{C}$ to $900^{\circ} \mathrm{C}$ and this process is known as the physical activation method. As for chemical activation, the biochar is commonly impregnated with chemicals such as zinc chloride $\left(\mathrm{ZnCl}_{2}\right)$ and phosphoric acid $\left(\mathrm{H}_{3} \mathrm{PO}_{4}\right)[2]$.

$\mathrm{AC}$ is an amorphous carbonaceous material derived from biochar which is from biomass, lignite and hard coal, synthetic materials and others. There are various sources for biochar such as palm kernel shells (PKS), rice husk, sugar cane and hazelnut shells. AC can appear in various shapes which are in powder form, granular form and pellet form [3]. The difference in sizes of the AC has different applications in industries. The characteristic of the $\mathrm{AC}$ varies with the source of biochar, the temperature of the pyrolysis process and the activation method. Sun et al. [4] reported that biochar from poultry residue has a larger surface area and porosity as compared to biochar derived from wheat straw even though both are produced under the same temperature whichis at $400{ }^{\circ} \mathrm{C}$. According to Ahmed et al. [5], modified biochar increases pore structure, surface area and also the functionality. In industry, the powdered AC ranges from $10 \mu \mathrm{m}-100 \mu \mathrm{m}$ and granular activated carbon (GAC) ranges from $0.4 \mathrm{~mm}$ $2.5 \mathrm{~mm}$ are preferred due to their diverse uses. However, GAC is more preferred as compared to the powdered one. According to Menya et al. [6], this is due to the particles size where the smaller AC needs to be separated from the water source after being applied. In addition, powdered AC has low bulk density, thus it needs to be added in a great volume to allow high adsorption of micro-pollution [7]. However, due to the high production and regeneration cost of GAC, it becomes a limitation to the application scale [8].

Palm kernel shell (PKS) is one of the solid biomass that is generated during palm fruitsprocessing in the palm oil industries. The reason to use PKS as the biomass for the biochar is due to the physicochemical properties such as high mechanical strength, porous surface, high chemical stability, various functional groups and insolubility in water [9]. According to Yuliusman et al. [10], PKS biochar (PKSB) is a good precursor for AC since it contains $26.6 \%$ cellulose and $27.7 \%$ hemicellulose. The high content of cellulose and hemicellulose in the PKSB contributes to the adsorption properties. There are a few types of pyrolysis processes that can be used to produce biochar from biomass which are slow pyrolysis, vacuum pyrolysis and fast pyrolysis. The yield of production for biochar and bio-oil is the highest when using either vacuum or slow pyrolysis process [11]. It was found that through a slow pyrolysis process, it could develop biochar with the highest surface area as compared to the vacuum pyrolysis process $[1,11,12]$. For the PKS, the physical activation process produced a minimal surface area of $167 \mathrm{~m}^{2} / \mathrm{g}$ and a maximum surface area of $607 \mathrm{~m}^{2} / \mathrm{g}$, whereby the chemical activation process produced a minimal surface area of $743 \mathrm{~m}^{2} / \mathrm{g}$ and a maximum surface area of $1295 \mathrm{~m}^{2} / \mathrm{g}$.

There is limited research that had been conducted on the chemical activation of PKS biochar derived from slow vacuum pyrolysis and combined with varying activation temperature, the concentration of $\mathrm{KOH}$ and particle sizes, on the quality of AC. Therefore, this study aimed to produce palm kernel shell granular activated carbon (PKSGAC) from slow vacuum pyrolysed PKSB via chemical activation using a horizontal tubular split zone furnace and to investigate the effects on varying parameters of the PKSGAC on its colour removal ability. The PKSB was activated through chemical activation using potassium hydroxide $(\mathrm{KOH})$ at various parameters such as activation temperature $\left(700^{\circ} \mathrm{C}\right.$ to $\left.850^{\circ} \mathrm{C}\right), \mathrm{KOH}$ concentration $(50 \% \mathrm{w} / \mathrm{v}$ to $100 \% \mathrm{w} / \mathrm{v})$ and particle size of PKSB $(0.4 \mathrm{~mm}$ to $2.5 \mathrm{~mm}$ ). The PKSGAC was characterized to determine their thermal condition, iodine number, bulk

e-ISSN: 2289-7771

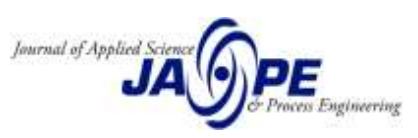


density, ash content, moisture content, surface area and morphology structure. The parameters that were used for each sample were determined by using the response surface methodology (RSM) based on central composite design (CCD). In this study, design expert version 11.0 software was used and three parameters as independent variables were manipulated. Finally, three different PKSGAC samples were used to test for the methylene blue (MB) dye removal.

\section{Materials and methods}

\subsection{Materials}

Commercial PKSB in the size range from $0.5 \mathrm{~cm}$ to $1 \mathrm{~cm}$ was provided by Borneo Energy Sdn. Bhd. Malaysia. For the activation process, a KOH pellet (ChemAR) was supplied by Classic Chemicals $\mathrm{Sdn}$. Bhd. Malaysia. As for the iodine number determination, the $0.1 \mathrm{~N}$ sodium thiosulfate solution; $\mathrm{HCl}$ with 37\% concentration and MB dye for colour removal application was purchased from Merck Sd. Bhd. Malaysia. The starch indicator solution was supplied by HACH Malaysia.

\subsection{Equipment}

The PKSB were ground using an automatic continuous hammer mill grinder at $2850 \mathrm{rpm}$ and separated according to their various sizes $(0.4 \mathrm{~mm}$ to $2.5 \mathrm{~mm})$ using a sieve shaker. The thermal behaviour of raw PKSB and the PKSGAC was studied by using the thermogravimetric analyzer (TGA/DSC, Mettler Toledo). The surface structure of the samples was determined by scanning electron microscope (SEM, Carl Zeiss MA10). The surface area for the PKSGAC was determined using the BET (Brunauer-Emmet-Teller) method. Ultraviolet-visible (UV-Vis) spectroscopy was used to determine the concentration of MB adsorbed.

\subsection{Preparation for PKSB sizes}

In order to prepare PKSGAC, the PKSB needed to have uniform sizes for every sample. The PKSB underwent size reduction and sieving by using a grinder and 3 different sieves mesh sizes of $2.36 \mathrm{~mm}$, $1.4 \mathrm{~mm}$ and $0.425 \mathrm{~mm}$ to obtain a PKSB particle size range of $0.4 \mathrm{~mm}$ to $2.5 \mathrm{~mm}$. The low hardness of PKSB allowed easy crushing despite minimal force exerted. However, during the sieving process, there were limited sieve sizes that could be used. The exact sieve sizes for the PKSB separation $(0.4 \mathrm{~mm}$ and $2.5 \mathrm{~mm}$ ) were not available. Hence, the nearest sieve sizes of $0.425 \mathrm{~mm}$ and $2.46 \mathrm{~mm}$ were used.

\subsection{Preparation of PKSGAC}

The $\mathrm{KOH}$ pellet was diluted with distilled water to achieve the desired concentrationwhich was from the range of $50 \% \mathrm{w} / \mathrm{v}$ to $100 \% \mathrm{w} / \mathrm{v}$ of $\mathrm{KOH}$. The dilution was conducted using the volumetric flask. It was then added with $30 \mathrm{~g}$ of PKSB withdifferent sizes inside a $250 \mathrm{ml}$ beaker. The mixture was sealed using an aluminium foil and shaken thoroughly to ensure the raw material and the activation agent were completely mixedand kept for $2 \mathrm{~h}$ at room temperature to ensure that the $\mathrm{KOH}$ could penetrate to the interior of the PKSB [13]. The mixture was filtered using a Whatman no.2V filter paper and a filter funnel. Then, the PKSB samples were heated inside the oven at $103{ }^{\circ} \mathrm{C}$ for $24 \mathrm{~h}$ using the beaker to remove the excess solution before being put inside the furnace for activation. All the samples were put through the activation process. The activation process involved placing the samples on a steel tray and subsequently placing them inside the furnace which was held at a temperature according to its respective parameters listed in Table 1. Vacuum condition was achieved by injecting nitrogen gas. After the carbonization process, the samples were washed with $3 \mathrm{M}$ of $\mathrm{HCl}$ and filtered using a beaker, filter paper and spatula. The acid-washing step removed the soluble salts and potassium compounds that resulted in the development of an accessible microporosity [13]. The mixture was then washed again with distilled

e-ISSN: 2289-7771

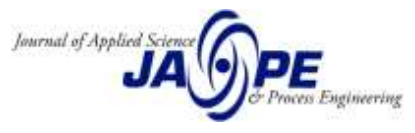


water until the solution reached a neutral $\mathrm{pH}$ of 7 . The samples needed to be washed with distilled water in order to get rid of chloride [10]. The preparation of the PKSGAC step was important to ensure that the pore structure of the sample could be seen clearly. This was because the process of washing with $\mathrm{HCl}$ and water could remove the potassium and basic compounds that blocked the pores. The samples were then dried in an oven at a temperature of $80^{\circ} \mathrm{C}$ until a constant weight was achieved and stored in an airtight container before beingcharacterized for its physical and chemical properties. The dried sample was weighed and the percentages of the yield of PKSGAC produce were calculated using equation 1.

Percent yield $(\%)=\frac{\text { Final mass }}{\text { Initial mass }} \times 100$

Response surface methodology (RSM) was used to optimize an output variable or the response, which was influenced by several input variables. The software was a collection of statistical and mathematical techniques for empirical model building, to form regression model equations $[14,15]$. In this RSM software, central composite design (CCD) was used as the model to obtain the set of experiments [14-16]. On the other hand, BBD had fewer design points and never included runs that had low settings. In this study, design expert version 11.0 software was used and three parameters as independent variables were manipulated. The maximum and minimum for every variable were set which were activation temperature (A) $\left(700{ }^{\circ} \mathrm{C}-850{ }^{\circ} \mathrm{C}\right), \mathrm{KOH}$ concentration $(\mathrm{B})(50 \%-100 \% \mathrm{w} / \mathrm{v})$ and particle size of PKSB (C) $(0.4 \mathrm{~mm}-2.5 \mathrm{~mm})$. The full design matrix consisted of 1 factorialpoint, 1 axial point and 4 replicates at the centre points. 18 experiments were conducted and collected data were fed into the RSM model. Results were produced in the form of equations and response surface graphs. Table 1 shows the experimental design found based on RSM.

Table 1. Set of experiments in the RSM model

\begin{tabular}{|c|c|c|c|}
\hline Run & $\begin{array}{c}\text { Factor 1 } \\
(\mathbf{A}) \mathbf{~}^{\mathbf{C}}\end{array}$ & $\begin{array}{c}\text { Factor 2 } \\
(\mathbf{B}) \mathbf{\%}\end{array}$ & $\begin{array}{c}\text { Factor 3 } \\
(\mathbf{C}), \mathbf{~ m m}\end{array}$ \\
\hline 1 & 700 & 50 & 0.40 \\
\hline 2 & 700 & 100 & 0.40 \\
\hline 3 & 700 & 50 & 2.50 \\
\hline 4 & 700 & 100 & 2.50 \\
\hline 5 & 700 & 75 & 1.45 \\
\hline 6 & 775 & 75 & 2.50 \\
\hline 7 & 775 & 75 & 1.45 \\
\hline 8 & 775 & 75 & 1.45 \\
\hline 9 & 775 & 75 & 1.45 \\
\hline 10 & 775 & 75 & 1.45 \\
\hline 11 & 775 & 50 & 1.45 \\
\hline 12 & 775 & 100 & 1.45 \\
\hline 13 & 775 & 75 & 0.40 \\
\hline 14 & 850 & 50 & 0.40 \\
\hline 15 & 850 & 100 & 0.40 \\
\hline 16 & 850 & 75 & 1.45 \\
\hline 17 & 850 & 100 & 2.50 \\
\hline 18 & 850 & 50 & 2.50 \\
\hline
\end{tabular}

The parameters needed to be varied in order to determine the optimum condition of the activation process that was able to achieve the desired quality of PKSGAC. The molarity of the $\mathrm{KOH}$ was 8.91 
$\mathrm{mol} / 1$ for $50 \%, 13.37 \mathrm{~mol} / 1$ for $75 \%$ and $17.82 \mathrm{~mol} / 1$ for $100 \%$ of $\mathrm{KOH}$. However, there was difficulty in obtaining the desired sizes for the PKSB. Thus, the nearest sieve sizes were used to sieve the PKSB which were $0.425 \mathrm{~mm}, 1.4 \mathrm{~mm}$ and $2.36 \mathrm{~mm}$.

\subsection{Characterization of PKSGAC}

Characterization analyses were important in order to understand the characteristics and properties of the PKSGAC. The PKSB was characterized to determine its thermal condition, and the PKSGAC was characterized to determine their iodine number, bulk density, ash content, moisture content, surface area and morphology structure.

\subsubsection{Thermal analysis}

The thermal stability of loaded and unloaded samples was evaluated using thermogravimetric analyzer TGA/DSC (Mettler Toledo). The initial PKSB sample weight was $22.50 \mathrm{mg}$ and the TGA/DSC was operated at a temperature of $10^{\circ} \mathrm{C} / \mathrm{min}$ at a nitrogen supply rate of $20 \mathrm{ml} / \mathrm{min}$. The temperature was increased from $30^{\circ} \mathrm{C}$ to $850^{\circ} \mathrm{C}$ before terminating the process at $900^{\circ} \mathrm{C}$.

\subsubsection{Iodine number}

The sodium thiosulfate $\left(\mathrm{Na}_{2} \mathrm{~S}_{2} \mathrm{O}_{3}\right)$ volumetric titration was used based on the ASTM D4607, 2006 to determine the iodine number of the samples. $0.2 \mathrm{~g}$ of PKSGAC was put into a $250 \mathrm{ml}$ Erlenmeyer flask equipped with a ground glass stopper. $10 \mathrm{ml}$ of $5 \% \mathrm{HCl}$ solution was added into the flask and swirled gently. The stopper was loosened and the sample was heated to boil for $30 \mathrm{~s}$. The sample was then removed and cooled at room temperature. $100 \mathrm{ml}$ of $0.1 \mathrm{~N}$ iodine solution was pipetted into the flask and was shaken vigorously for $30 \mathrm{~s}$. The mixture was filtered using filter paper (Whatman number $2 \mathrm{v}$ ). First, $30 \mathrm{ml}$ of the filtrates were used to rinse the pipette. The filtrate was swirled and $50 \mathrm{ml}$ of it was pipetted into a clean $250 \mathrm{ml}$ Erlenmeyer flask. The filtrate was titrated with $0.1 \mathrm{~N} \mathrm{Na}_{2} \mathrm{~S}_{2} \mathrm{O}_{3}$ solution until the solution turned yellow. $2 \mathrm{ml}$ of the starch indicator was added and the titration continued until the solution turned colourless. The volume of $\mathrm{Na}_{2} \mathrm{~S}_{2} \mathrm{O}_{3}$ used was recorded. The iodine number $\left(\frac{X}{M}\right)$ per gram of carbon was calculated using equation 2 .

Iodine number $\left(\frac{X}{M}\right)=\frac{A-(D F)(B)(S)}{M}$

Where, $A=\left(\mathrm{N}_{2}\right)$ iodine $(12693.0) ; \mathrm{N}_{2}=$ iodine $(\mathrm{N})=0.1 \mathrm{~N} ; D F=$ dilution factor $=(100+10) / 50=2.2 ; B$ $=\left(\mathrm{N}_{1}\right)(126.93) ; \mathrm{N}_{1}=\mathrm{Na}_{2} \mathrm{~S}_{2} \mathrm{O}_{3}(\mathrm{~N})=0.1 \mathrm{~N} ; S=\mathrm{Na}_{2} \mathrm{~S}_{2} \mathrm{O}_{3}(\mathrm{ml})$

The second titration with $\mathrm{Na}_{2} \mathrm{~S}_{2} \mathrm{O}_{3}$ was done in order to detect the presence of iodine. The blueblack colour solution turned colourless when there was no iodine present in the solution. This total amount of $\mathrm{Na}_{2} \mathrm{~S}_{2} \mathrm{O}_{3}$ used in order to change the color of the solution to colorless was recorded to calculate the iodine number for the sample.

\subsubsection{Bulk density}

Bulk density was calculated according to the estimation by using the measuring cylinder. The PKSGAC samples were put inside the $10 \mathrm{ml}$ measuring cylinder. There were two repetitions and the average was taken for bulk density determination. Bulk density was calculated using equation 3 . 
Bulk density $\left(\frac{\mathrm{g}}{\mathrm{cm}^{3}}\right)=\frac{P K S G A C \text { weight in } 10 \mathrm{ml} \text { of measuring cylinder }}{10 \mathrm{~cm}^{3}}$

\subsubsection{Ash content}

The standard test method for ash content followed the ASTM D2866-94. A cruciblewas preheated in the furnace to about $600^{\circ} \mathrm{C}$, cooled in a desiccator and weighed. $1 \mathrm{~g}$ of sample was put into the crucible and reweighed. The sample was then put inside the cold furnace and the temperature was allowed to rise to $600^{\circ} \mathrm{C}$. The sample was heated with the presence of oxygen for 4 hours. It was then cooled in a desiccator at room temperature and reweighed. For each test, therewere two repetitions. The ash content was calculated using equation 4.

Ash content, $\%=\frac{\text { Weight of sample after ash process, } g}{\text { Weight of sample before ash process, } g} \times 100$

\subsubsection{Moisture content}

A thermal drying method was used where $1 \mathrm{~g}$ of sample was weighed, put inside the crucibles and reweighed. The sample was placed inside the oven at $103^{\circ} \mathrm{C}$ to constant weight for $24 \mathrm{~h}$. Then, the sample was reweighed and the moisture content was calculated. For the moisture content, it was repeated two times.

Moisture content, $\%=\frac{\text { Loss in weight on drying, } g}{\text { Initial sample weight, } g} \times 100$

\subsubsection{Surface area}

The specific surface area was determined by using the Brunauer-Emmett-Teller (BET) method (Vsorb 4800S) with adsorption-desorption isotherm of nitrogen at $-196{ }^{\circ} \mathrm{C}$. The specific surface area was determined according to the BET method at the relative pressure at $33.5 \mathrm{~atm}$. The sample was preheated at $150{ }^{\circ} \mathrm{C}$ under vacuum conditions. The time for degassing was $8 \mathrm{~h}$ under nitrogen conditions.

\subsubsection{Morphology structure}

The surface structure of the raw PKSB and PKSGAC samples were determined from the micrograph obtained from the scanning electron microscope (SEM, Carl Zeiss MA10). The samples were coated with gold before being analyzed with an operating condition of electron high tension (EHT) at $15 \mathrm{kV}$, the working distance (WD) at $7 \mathrm{~mm}$ and magnification power were between $5 \mathrm{X}$ and $2.00 \mathrm{kX}$. This process was conducted under pressure vacuum mode.

\subsection{Application for colour removal}

Three different PKSGAC samples were selected from Table 1. The samples were selected based on the conditions in which they were chemically activated. According to the literature, the optimum activation temperature range from $700{ }^{\circ} \mathrm{C}$ to $850^{\circ} \mathrm{C}[10,17]$. The three samples selected represented samples from three treatment temperatures (i.e. $700^{\circ} \mathrm{C}, 775^{\circ} \mathrm{C}$ and $850^{\circ} \mathrm{C}$ ), three $\mathrm{KOH}$ concentrations $(50 \% \mathrm{w} / \mathrm{v}, 75 \% \mathrm{w} / \mathrm{v}$, and $100 \% \mathrm{w} / \mathrm{v})$ and two-particle sizes (i.e. $0.4 \mathrm{~mm}$ and $2.5 \mathrm{~mm}$ ) and were used to test for the colour removal of MB with concentrations of $5 \mathrm{mg} / 1,10 \mathrm{mg} / 1,15 \mathrm{mg} / \mathrm{l}$ and $20 \mathrm{mg} / \mathrm{l}$. They 
were samples from various combinations of these conditions and named with a code number according to their activation condition, i.e. 850-50-2.5, 700-100-0.4 and 775-75-0.4 following the sequence of activation temperature, $\mathrm{KOH}$ concentration and particle size. These conditions were chosen to show the breadth of the effect of the conditions on the MB removal.

$0.02 \mathrm{~g}$ of MB dye was dissolved with $1000 \mathrm{ml}$ distilled water in a 11 volumetric flask. The initial concentration for the MB dye was $20 \mathrm{mg} / \mathrm{l}$. The MB solution was diluted using a pipette with distilled water to obtain the concentration ranging from $5 \mathrm{mg} / 1$ to $20 \mathrm{mg} / \mathrm{l}$. The prepared MB solution with different concentrations was checked with ultraviolet-visible (UV-Vis) spectroscopy to construct the calibration curve. $25 \mathrm{ml}$ of MBsolution with known initial concentration was mixed with $0.2 \mathrm{~g}$ of PKSGAC samples. The mixture was put inside the $150 \mathrm{ml}$ Erlenmeyer flasks with an airtight stopper. The mixture was shaken in a temperature-controlled shaker water bath at $60^{\circ} \mathrm{C}$ for $50 \mathrm{~min}$ [18]. The concentration of MB solution was determined by using UV-Vis spectroscopy at $\lambda_{\max } 660 \mathrm{~nm}$. The percentage of MB dye removed was calculated using equation 6.

$\%$ Dye removal $=\frac{C_{0}-C_{e}}{C_{0}} \times 100$

Where, $C_{o}$ is the initial concentration of $\mathrm{MB}, \mathrm{mg} / \mathrm{l} ; C_{e}$ is the concentration at equilibrium, $\mathrm{mg} / \mathrm{l}$

\section{Results and discussion}

\subsection{Thermal analysis}

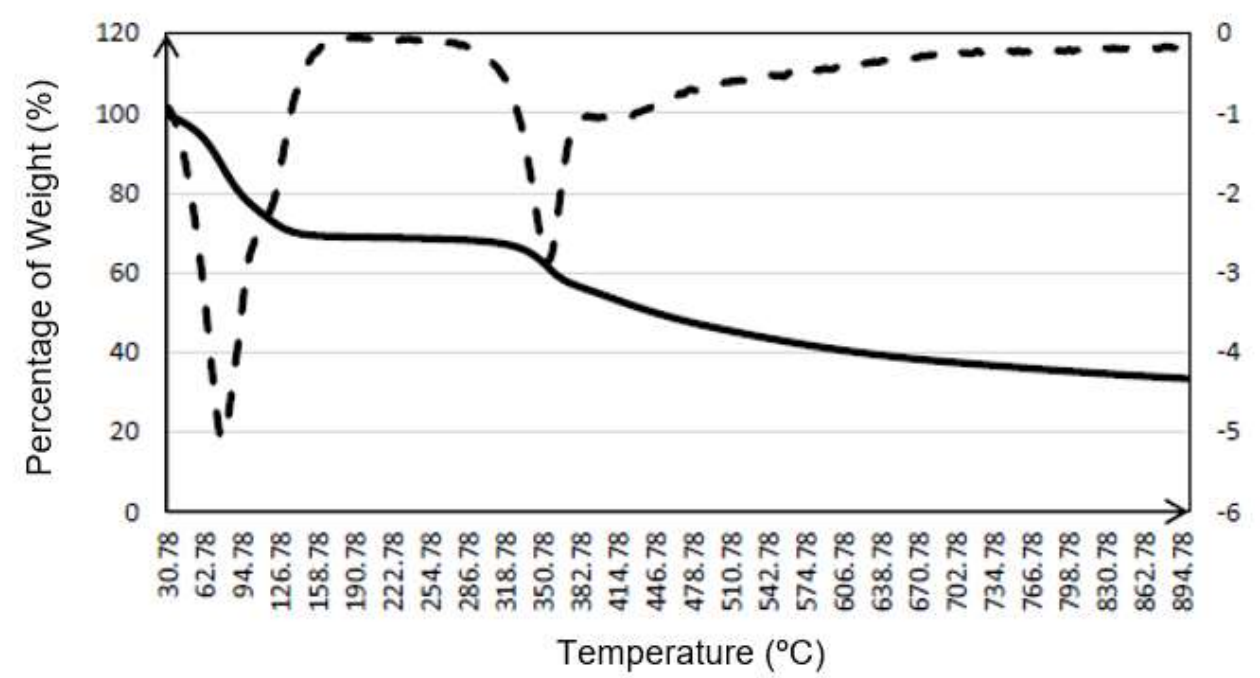

Figure 1. TGA analysis for the PKSB

Figure 1 shows the result for the thermal decomposition properties of the PKSB with a total of four peaks and the first peak appeared below $120^{\circ} \mathrm{C}$. It indicated that the evaporation of light was usually a volatile matter. Since the sample needed to be heated at a high temperature, the more volatile component evaporated at $120^{\circ} \mathrm{C}$. The second, third and fourth peaks indicated the decomposition of hemicellulose, cellulose and lignin. The TGA curve showed that the amount of char left at the end of the pyrolysis process was $33.39 \%$ that was equivalent to $7.51 \mathrm{mg}$. The amount of residue was high even after the huge weight loss for the sample. This was due to the larger particle size of the sample which was around 0.5 to $1 \mathrm{~cm}$. A previous study stated that the larger particles size yielded more residue due 
to the poor heat transfer to the inner biomass surface that led to low average particle temperature [19]. The first weight loss happened from $30.96{ }^{\circ} \mathrm{C}$ to $114.96{ }^{\circ} \mathrm{C}$. The maximum peak of weight loss rates attributed to water and organic vaporization with the peak at $78.78^{\circ} \mathrm{C}$ and weight derivative of $-5.04 \% / \mathrm{m}$. The second regime was between $260^{\circ} \mathrm{C}$ to $370^{\circ} \mathrm{C}$ for hemicellulose and cellulose with the peak at $355.78^{\circ} \mathrm{C}$ and derivative weight of $-2.85 \% / \mathrm{m}$. The third regime was from $400^{\circ} \mathrm{C}$ to $460^{\circ} \mathrm{C}$. It indicated the lignin decomposition with the peak at $406.78^{\circ} \mathrm{C}$ and derivative weight of $-1.07 \% / \mathrm{m}$. From Figure 1 , there were no significant changes in the weight loss for the sample at a temperature between $120^{\circ} \mathrm{C}$ until $320^{\circ} \mathrm{C}$. The total weight loss of the sample was $58.30 \%$ which was $13.12 \mathrm{mg}$ from $22.50 \mathrm{mg}$ of PKSB in the initial. Figure 2 shows the DSC curve for PKSB. Figure 2 shows the peaks of solid freezing which indicated that the heat was released for PKSGAC. The peaks showed at $78.8^{\circ} \mathrm{C}$ which was the melting temperature with a peak height of $9.84 \mathrm{MV}$.

Table 2 shows the raw data from the characterization of the PKSGAC obtained from the 18 experiments as suggested by the RSM listed in Table 1; percent yield, iodine number, bulk density, ash and moisture content for PKSGAC. The raw data was used in the RSM to develop the polynomial model equations.

Table 2. Raw data from the characterization of the PKSGAC

\begin{tabular}{|c|c|c|c|c|c|c|c|c|}
\hline $\begin{array}{c}\text { Temperature } \\
\left({ }^{\circ} \mathrm{C}\right)\end{array}$ & $\begin{array}{c}\text { Concent } \\
\text { ration } \\
(\%)\end{array}$ & $\begin{array}{c}\text { Size } \\
(\mathrm{mm})\end{array}$ & $\begin{array}{l}\text { Percent } \\
\text { yield }\end{array}$ & $\begin{array}{c}\text { Amount } \\
\text { of } \\
\mathrm{Na}_{2} \mathrm{~S}_{2} \mathrm{O}_{3} \\
(\mathrm{ml})\end{array}$ & $\begin{array}{c}\text { Iodine } \\
\text { number } \\
\text { (mg/g) }\end{array}$ & $\begin{array}{c}\text { Bulk } \\
\text { density } \\
\left(\mathrm{g} / \mathrm{cm}^{3}\right)\end{array}$ & $\begin{array}{c}\text { Ash } \\
\text { content } \\
(\%)\end{array}$ & $\begin{array}{c}\text { Moisture } \\
\text { content } \\
(\%)\end{array}$ \\
\hline \multirow[t]{5}{*}{700} & 50 & 0.40 & 90.33 & 29.4 & 224.16 & 0.47 & 8 & 32 \\
\hline & 100 & 0.40 & 42.67 & 30.8 & 204.61 & 0.20 & 9 & 1 \\
\hline & 50 & 2.50 & 89.33 & 29.3 & 225.56 & 0.50 & 2 & 27 \\
\hline & 100 & 2.50 & 60.00 & 41.6 & 538.18 & 0.29 & 4 & 1 \\
\hline & 75 & 1.45 & 59.33 & 41.1 & 607.99 & 0.40 & 12 & 1 \\
\hline \multirow[t]{8}{*}{775} & 75 & 2.50 & 96.33 & 41.3 & 580.07 & 0.46 & 7 & 40 \\
\hline & 75 & 1.45 & 51.67 & 39.7 & 803.47 & 0.24 & 9 & 0 \\
\hline & 75 & 1.45 & 51.43 & 39.8 & 789.51 & 0.33 & 8 & 0 \\
\hline & 75 & 1.45 & 49.77 & 39.5 & 831.39 & 0.27 & 6 & 1 \\
\hline & 75 & 1.45 & 51.70 & 39.7 & 803.47 & 0.21 & 9 & 1 \\
\hline & 50 & 1.45 & 43.00 & 39.4 & 845.35 & 0.23 & 8 & 0 \\
\hline & 100 & 1.45 & 63.00 & 38.1 & 1026.86 & 0.17 & 7 & 9 \\
\hline & 75 & 0.40 & 54.67 & 39.7 & 803.47 & 0.30 & 8 & 1 \\
\hline \multirow[t]{5}{*}{850} & 50 & 0.40 & 42.33 & 36.0 & 1320.07 & 0.34 & 8 & 0 \\
\hline & 100 & 0.40 & 43.20 & 38.7 & 943.09 & 0.35 & 6 & 39 \\
\hline & 75 & 1.45 & 43.00 & 39.0 & 901.20 & 0.29 & 6 & 0 \\
\hline & 100 & 2.50 & 33.23 & 40.0 & 761.58 & 0.21 & 7 & 4 \\
\hline & 50 & 2.50 & 64.67 & 40.2 & 733.655 & 0.45 & 8 & 0 \\
\hline
\end{tabular}

From Table 2, it can be seen that the range of the product yield was between $33.23 \%$ and $96.33 \%$. According to Adinata et al. [20], when higher impregnation ratios were used, the release of volatile products increased. This was due to the increased dehydration and elimination reactions. This gave a higher weight loss of produced PKSGAC. This could be proven from the data obtained were at the same PKSGAC size and $\mathrm{KOH}$ concentration which were $2.5 \mathrm{~mm}$ and $100 \% \mathrm{w} / \mathrm{v}$, the yield decreased from $60 \%$ to $33.23 \%$ with the activation temperature of $700^{\circ} \mathrm{C}$ and $850^{\circ} \mathrm{C}$ respectively. It can be seen that the higher iodine number was achieved with the particle size of $0.4 \mathrm{~mm}$, temperature $850^{\circ} \mathrm{C}$ and concentration $50 \% \mathrm{w} / \mathrm{v}$ with $1320.07 \mathrm{mg} / \mathrm{g}$ (Table 2). The second highest iodine number achieved was $1026 \mathrm{mg} / \mathrm{g}$ for activation temperature of $775^{\circ} \mathrm{C}, \mathrm{KOH}$ concentration of $100 \% \mathrm{w} / \mathrm{v}$, the particle size of 
$1.45 \mathrm{~mm}$ with a total of $38.1 \mathrm{ml}$ of $\mathrm{Na}_{2} \mathrm{~S}_{2} \mathrm{O}_{3}$. The high amount of iodine number indicated there was a high amount of iodine that was being adsorbed by the PKSGAC.

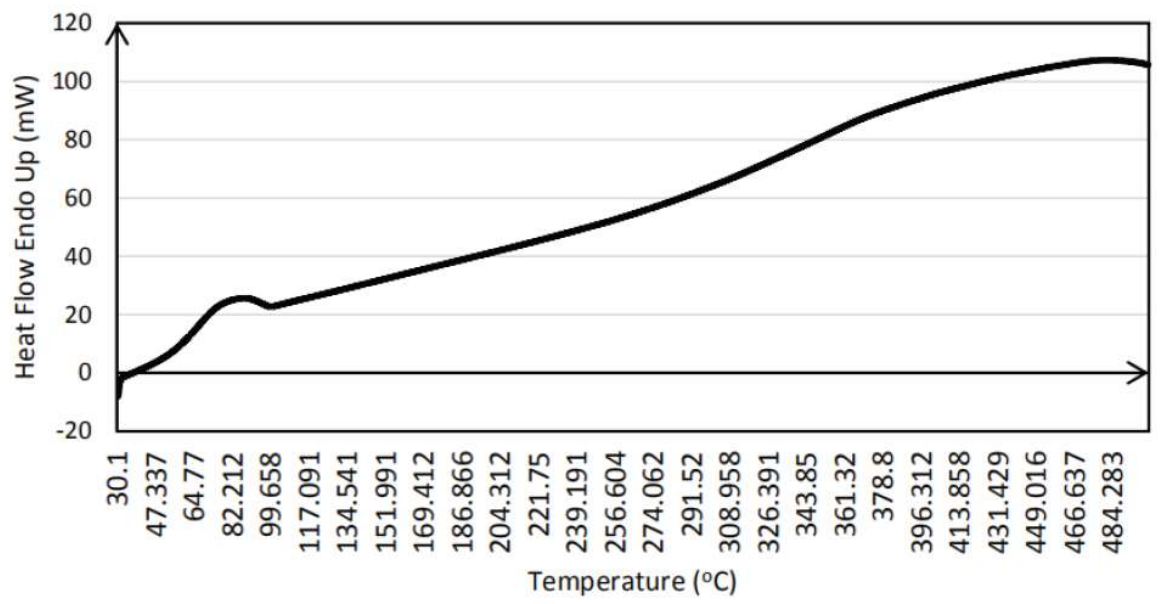

Figure 2. DSC analysis for PKSB

Table 2 shows that the value for moisture content ranged from $0 \%-39 \%$, the ash content value ranged from $2 \%-12 \%$, while bulk density ranged from $0.17 \mathrm{~g} / \mathrm{cm}^{3}-0.50 \mathrm{~g} / \mathrm{cm}^{3}$ respectively. Based on the collected data, the bulk density, ash content and moisture content were related to each other. The lower amount of moisture and ash indicated that the bulk density was relatively small. The amount of ash content inside the PKSGAC affected the application of the AC. The higher ash content reduced the overall activity of the AC and also reduced the efficiency for reactivation [21]. Therefore, the lower amounts of ash content showed better adsorbent performance. Lower moisture content in AC improved its quality as water vapour competed in the adsorption process to fill the adsorption sites within the pores. Higher moisture reduces the efficiency of AC [22]. Bulk density was used to determine the mass of carbon that could be contained in a filter of a given solids capacity and the amount of treated liquid that could be retained by the filter cake [21].

The experimental data obtained in Table 2 were used to calculate the coefficients of the quadratic polynomial equation. The regression equation for the response variables in terms of coded factors, obtained through RSM are given to the equations (7-11):

Percent yield (\%)

$$
\begin{aligned}
& =54.78-11.42 A-8.79 B+7.04 C+5.80 A B-0.4950 A C-1.75 B C-7.27 A^{2} \\
& -5.44 B^{2}+17.06 C^{2}
\end{aligned}
$$

Iodine number $(\mathrm{mg} / \mathrm{g})$

$$
\begin{aligned}
& =-17499.16238+39.70331 A+11.28012 B+1483.98419 C-0.042809 A B \\
& -1.75063 A C+3.50992 B C-0.019447 A^{2}+0.115397 B^{2}-156.20599 C^{2}
\end{aligned}
$$

Moisture content, $\%$

$$
\begin{aligned}
& =2.69-1.90 A-0.5 B-0.1 C+12.5 A B-3.75 A C-3.75 B C-4.38 A^{2} \\
& -0.3810 B^{2}+15.62 C^{2}
\end{aligned}
$$

Ash content, $\%=7.33-0.1 B-1.1 C-0.75 A B+1.5 A C+0.25 B C$ 


$$
\begin{aligned}
\text { Bulk content } & \left(\frac{g}{c m^{3}}\right) \\
& =0.2705-0.0221 A-0.0777 B+0.0245 C+0.0305 A B-0.0193 A C \\
& -0.0243 B C+0.0641 A^{2}-0.0809 B^{2}+0.0991 C^{2}
\end{aligned}
$$

Where, $\mathrm{A}$ is activation temperature $\left({ }^{\circ} \mathrm{C}\right), \mathrm{B}$ is $\mathrm{KOH}$ concentration $(\% \mathrm{w} / \mathrm{v})$ and $\mathrm{C}$ is particle size $(\mathrm{mm})$.

In the regression equations, the negative sign assigned for the coefficient indicated an inverse effect between the factor and the response variable. Conversely, the positive sign indicated a synergistic effect [23]. Figure 3 shows the 3D graphic surface for the percent yield of the PKSGAC activated.

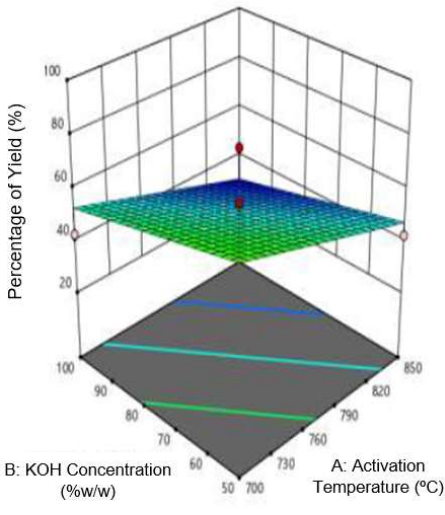

(a)

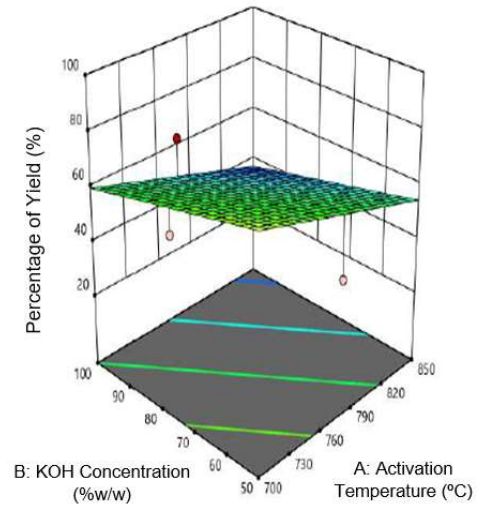

(b)

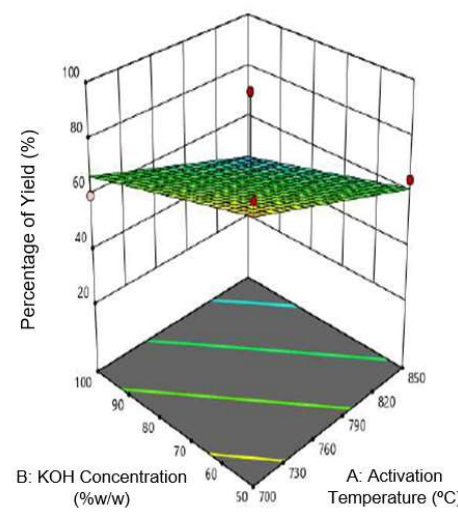

(c)

Figure 3. 3D graphic surface for the yield percentage of the PKSGAC according to size (a) $0.4 \mathrm{~mm}$, (b) $1.4 \mathrm{~mm}$, and (c) $2.5 \mathrm{~mm}$

Figure 3 shows the percentage of yield for the PKSGAC that is separated according to the size of the sample. As the particle size of the PKSGAC increased, the percentage of yield increased.This was because as the sample particle size increased, they were not uniformly heated. Not only that, the larger particles size yielded more residue due to the poor heat transfer to the inner biomass surface that led to low average particle temperature [19]. Furthermore, as the temperature increases, it would result in a decrease in the yield. This was due to the wall of the AC starting to collapseat high activation temperature and $\mathrm{KOH}$ concentration. Next, the overall data was inserted into the RSM. This method helps to predict the suitable activation condition which achieves the nearest expected value. Figure 4 shows the suggested solution using RSM for CCD.

From Figure 4, it can be seen that by using the activation temperature of $850^{\circ} \mathrm{C}$, the $\mathrm{KOH}$ concentration of $69.22 \% \mathrm{w} / \mathrm{v}$ and the sample particle size of $0.59 \mathrm{~mm}$, might result in the nearest desired quality. The results were predicted to be $6.58 \%$ of moisture content, $7.25 \%$ of ash content, $0.38 \mathrm{~g} / \mathrm{cm}^{3}$ for bulk density and $1100 \mathrm{mg} / \mathrm{g}$ for iodine number. Figure 5 shows the 3D graphic surface for the iodine number of PKSGAC.

Figure 5 shows that the PKSGAC with $0.4 \mathrm{~mm}$ particle size produced a $3 \mathrm{D}$ response surface plot with the highest iodine number of $1320 \mathrm{mg} / \mathrm{g}$ which was achieved at $50 \% \mathrm{w} / \mathrm{v} \mathrm{KOH}$ and activation temperature of $850{ }^{\circ} \mathrm{C}$. For $0.4 \mathrm{~mm}$ particle size, to achieve above $950 \mathrm{mg} / \mathrm{g}$ iodine number, the minimum temperature and $\mathrm{KOH}$ concentration must be at least $770{ }^{\circ} \mathrm{C}$ and $50 \% \mathrm{w} / \mathrm{v}$, respectively. Colours between yellow to red signified the iodine number of $950 \mathrm{mg} / \mathrm{g} 1320 \mathrm{mg} / \mathrm{g}$. For PKSGAC 1.4 $\mathrm{mm}$ particle size, colours between yellow to orange could achieve an iodine number of $950 \mathrm{mg} / \mathrm{g} 1100$ 
$\mathrm{mg} / \mathrm{g}$ for temperatures above $790{ }^{\circ} \mathrm{C}$ at any concentration from $50-100 \% \mathrm{w} / \mathrm{v}$. It was found that at a temperature less than $790{ }^{\circ} \mathrm{C}$, the iodine number was low. Hence, at $1.4 \mathrm{~mm}$, to save energy and cost, it was best to choose $790{ }^{\circ} \mathrm{C}$ and $50 \%$ w/v KOH. The PKSGAC with $2.5 \mathrm{~mm}$ particle size could only achieve an iodine number of just below $800 \mathrm{mg} / \mathrm{g}$ at $790^{\circ} \mathrm{C}$ and $100 \% \mathrm{w} / \mathrm{v} \mathrm{KOH}$.
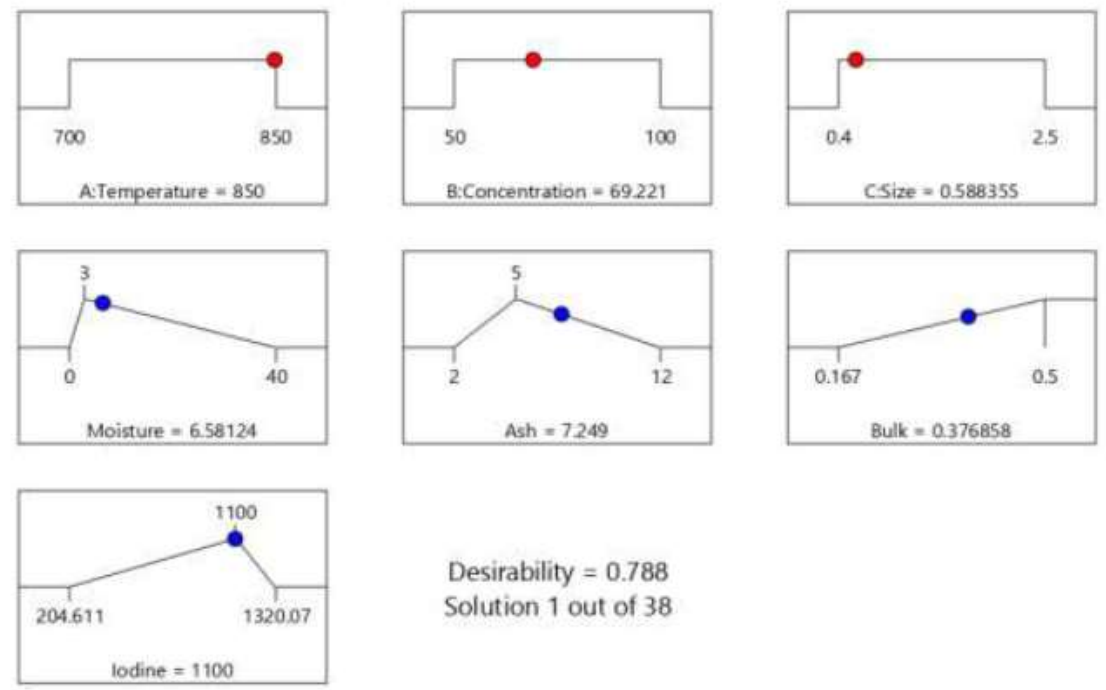

Desirability $=0.788$

Solution 1 out of 38

Figure 4. Suggested solution using the RSM for the CCD

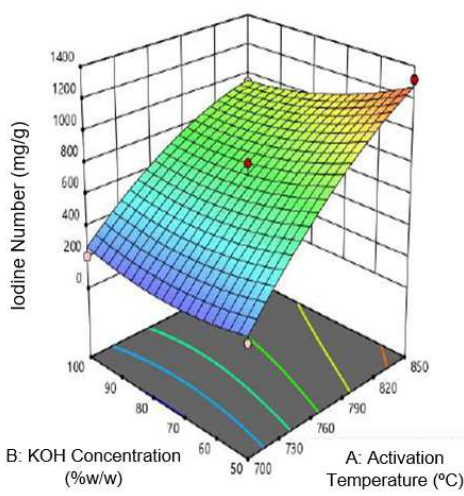

(a)

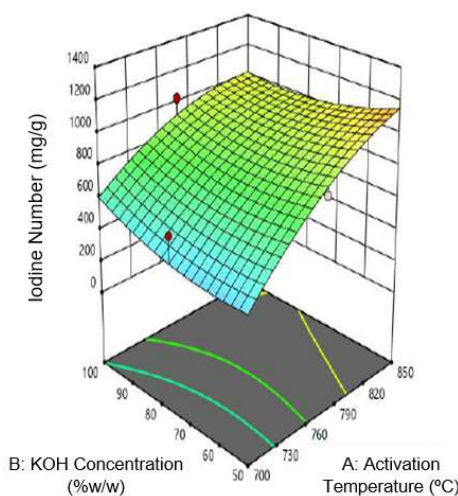

(b)

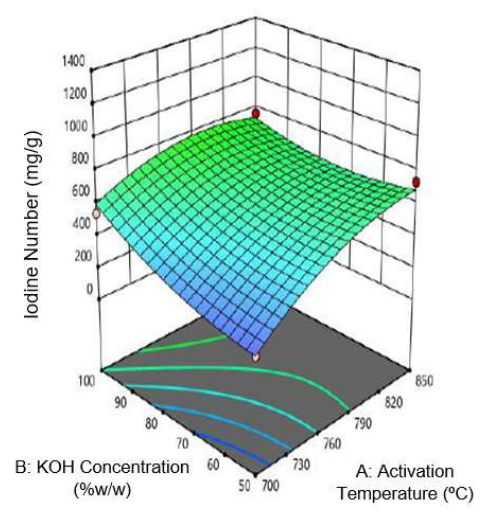

(c)

Figure 5. 3D graphic surface for the iodine number of PKSGAC according to size (a) $0.4 \mathrm{~mm}$ (b) 1.4 $\mathrm{mm}$, dan (c) $2.5 \mathrm{~mm}$

Generally, for constant size and $\mathrm{KOH}$ concentration, it is observed that at a higher activation temperature, the iodine number was higher. This was because at a higher activation temperature, more pores were formed and more iodine could be adsorbed from the solution. For each particle size, at constant activation temperature, the variation of the iodine number according to the $\mathrm{KOH}$ concentration was less pronounced. The iodine adsorption of AC slightly increased with increasing $\mathrm{KOH}$ concentration [24,25]. This was due to the increased micropore content on the surface of AC. However, at a higher activation temperature, the micropores would decrease at higher $\mathrm{KOH}$ concentrations due to excess carbon burn off. For $0.4 \mathrm{~mm}$, the minimum temperature of $775^{\circ} \mathrm{C}$ and $\mathrm{KOH}$ concentration of 
$50 \% \mathrm{w} / \mathrm{v}$ were needed to achieve an iodine number of $950 \mathrm{mg} / \mathrm{g}$. The temperature needed to be increased to achieve a higher iodine number. In terms of particle size, it seemed that the variation of iodine number for the $0.4 \mathrm{~mm}$ was larger. This was due to the smaller particle size having a larger exposed surface area.

\subsection{Surface area}

From the BET analysis, the PKSGAC sample obtained $581 \mathrm{~m}^{2} / \mathrm{g}$ for $\mathrm{S}_{\mathrm{BET}}$ and $0.3173 \mathrm{~cm}^{3} / \mathrm{g}$ for the $\mathrm{V}_{\text {tot. }}$ The iodine number for this sample was $580.07 \mathrm{mg} / \mathrm{g}$. Figure 6 shows nitrogen gas adsorptiondesorption isotherms of $\mathrm{GAC}$ at $775^{\circ} \mathrm{C}, 755 \% \mathrm{w} / \mathrm{v}$ and $2.5 \mathrm{~mm}$.

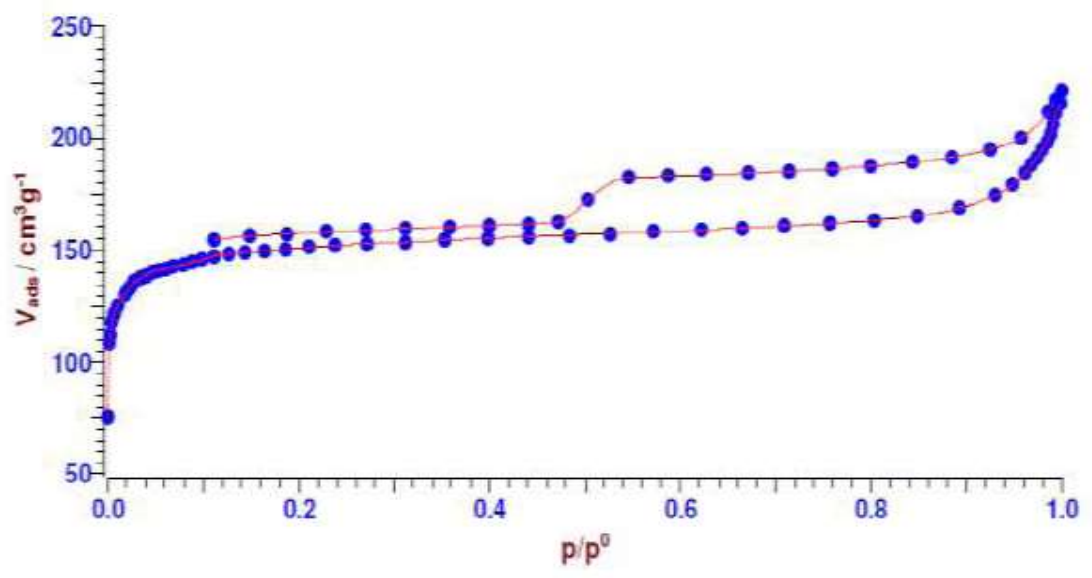

Figure 6. Nitrogen gas adsorption-desorption isotherms of PKSGAC at $775^{\circ} \mathrm{C}, 75 \% \mathrm{w} / \mathrm{v}$, and $2.5 \mathrm{~mm}$

Figure 6 shows obvious decreases in nitrogen adsorption values at moderate and high relative pressure. This indicated the significant widening of microporosity and rapid increases of mesoporosity or even macro-porosity contribution [26]. The isotherm also showed nitrogen adsorption at relative pressure close to 1 . This meant that the development of macropores was caused by the widening of micropores and mesopores. Figure 7 displays the pore size distribution for PKSGAC at $775{ }^{\circ} \mathrm{C}, 75 \%$ $\mathrm{w} / \mathrm{v}$, and $2.5 \mathrm{~mm}$. As shown in Figure 7, the pore volume increased less than $6 \mathrm{~nm}$ and the width of the peak showed the pore size of the PKSGAC.

The values of iodine number and $\mathrm{S}_{\mathrm{BET}}$ were comparable as confirmed by other researchers. The specific surface area could be estimated by using the iodine number measured during the experiment. The iodine number was used as a relative indicator of porosity in an $\mathrm{AC}$ and it did not necessarily measure the carbon's abilityto adsorb other species. Table 3 shows the comparison between the iodine number and the surface area. 


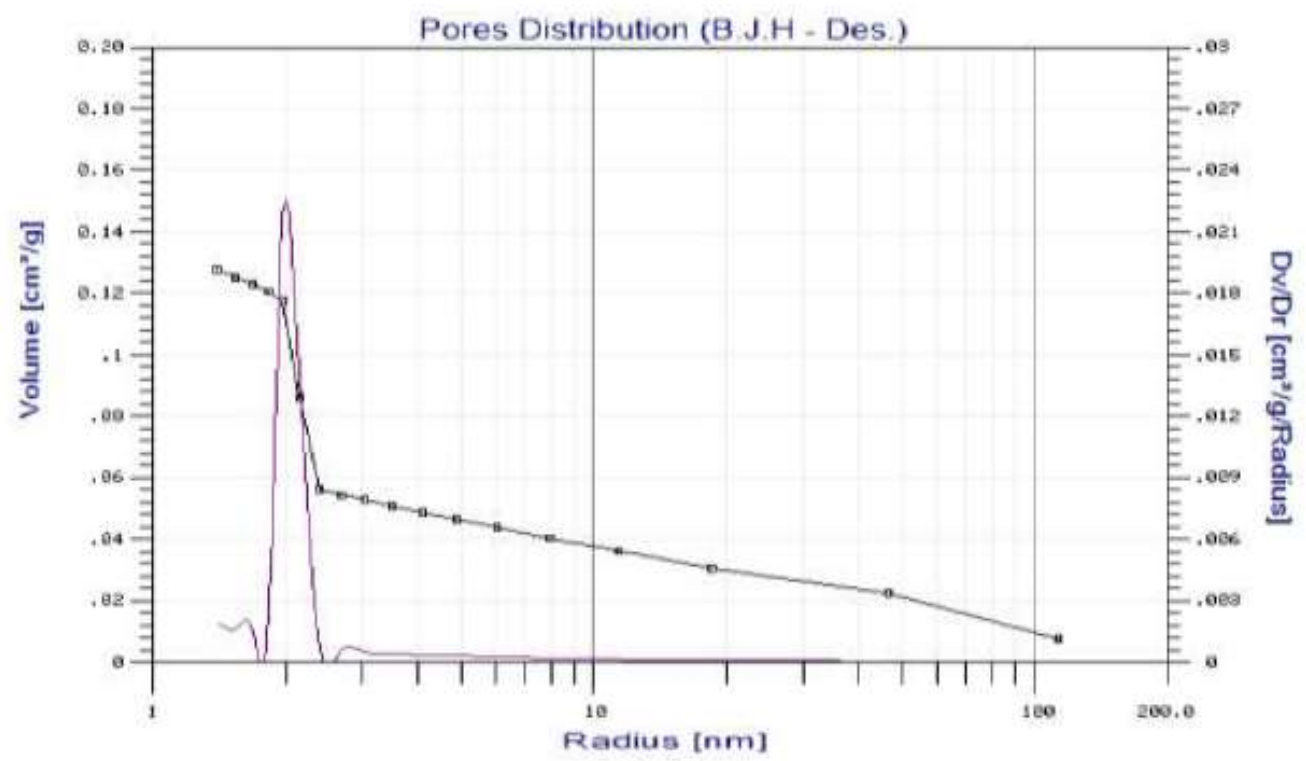

Figure 7. Pore size distribution for PKSGAC at $775^{\circ} \mathrm{C}, 75 \% \mathrm{w} / \mathrm{v}$, and $2.5 \mathrm{~mm}$

Table 3. Comparison between iodine number and surface area

\begin{tabular}{|c|c|c|c|c|}
\hline Raw material & Activation process & $\begin{array}{c}\text { Iodine number } \\
(\mathbf{m g} / \mathbf{g})\end{array}$ & $\begin{array}{c}\text { Surface area } \\
\left(\mathbf{m}^{2} / \mathbf{g}\right)\end{array}$ & References \\
\hline PKS & $\begin{array}{c}\text { Chemical activation }(\mathrm{KOH}), \\
850^{\circ} \mathrm{C}, 1: 4 \text { ratio }\end{array}$ & 648 & 743 & {$[10]$} \\
\hline Biochar & $\begin{array}{c}\text { Chemical activation }(\mathrm{KOH}), \\
\text { Size sample }(150-600 \mu \mathrm{m}), \\
812.5^{\circ} \mathrm{C}, 1.63 \text { ratio }\end{array}$ & 1576 & 1578 & {$[13]$} \\
\hline $\begin{array}{c}\text { Polyethylene } \\
\text { terephthalate }(\mathrm{PET}) \\
\text { waste }\end{array}$ & $\begin{array}{r}\text { Physical activation }\left(\mathrm{CO}_{2}\right), \\
950^{\circ} \mathrm{C}\end{array}$ & 209.59 & 211.9 & {$[26]$} \\
\hline PKSB & $\begin{array}{c}\mathrm{Chemical} \mathrm{activation,} 775^{\circ} \mathrm{C}, \\
75 \% \mathrm{w} / \mathrm{V}(\mathrm{KOH}), \mathrm{particle} \\
\text { size } 2.5 \mathrm{~mm}\end{array}$ & 580.07 & 581 & This work \\
\hline
\end{tabular}

Table 3 shows the minimal difference between the iodine number and the surface area. The slight difference in the result was due to the presence of components such as adsorbed volatiles, sulfur and water that affect the iodine number measured for the AC (ASTM D 4607-94, 2006). In this study, the iodine number was $580.07 \mathrm{mg} / \mathrm{g}$ and the BET surface area was $581 \mathrm{~m}^{2} / \mathrm{g}$. There was not much difference between both of the values. Most of the data from previous research showed a low iodine number despite the high BET results. This iodine number could only be used as an approximation for the surface area and not determine the exact BET result. 


\subsection{Morphology structure}

Figure $8(\mathrm{a}, \mathrm{b})$ shows the SEM morphology structure for raw PKSB with $2.5 \mathrm{~mm}$ particle size while Figure 8 (c, d) for PKSGAC samples with $700{ }^{\circ} \mathrm{C}$ of activation temperature, $50 \% \mathrm{w} / \mathrm{w}$ of $\mathrm{KOH}$ concentration and $2.5 \mathrm{~mm}$ particle size. The lower activation temperature and $\mathrm{KOH}$ concentration were chosen to ensure that chemical activation using $\mathrm{KOH}$ at that condition started to show pore development [25].

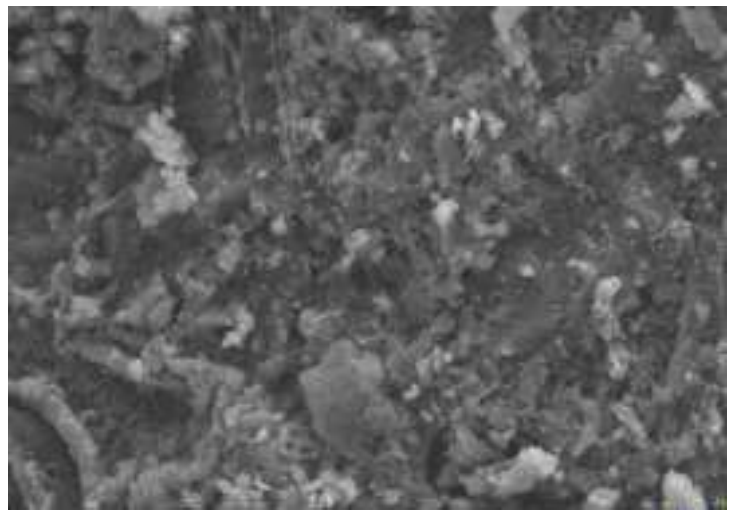

(a)

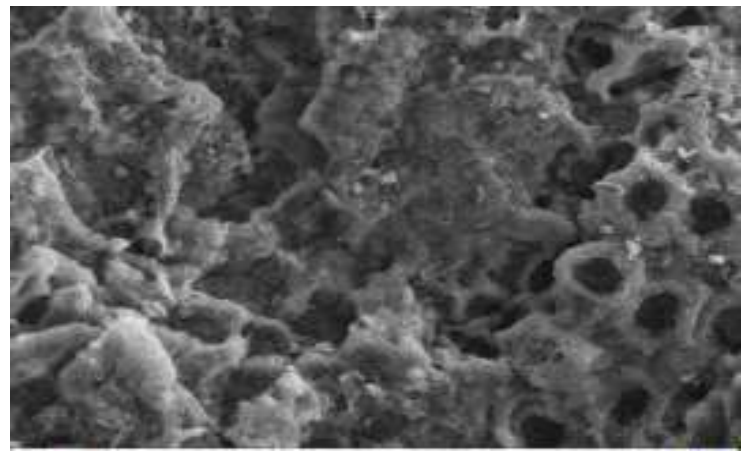

(c)

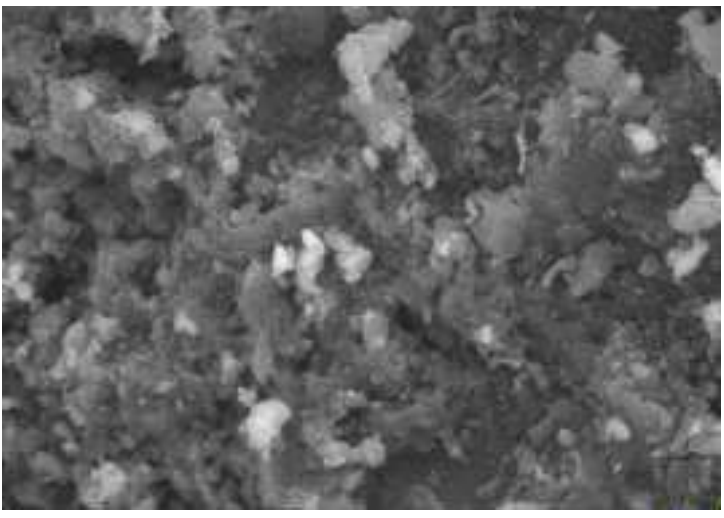

(b)

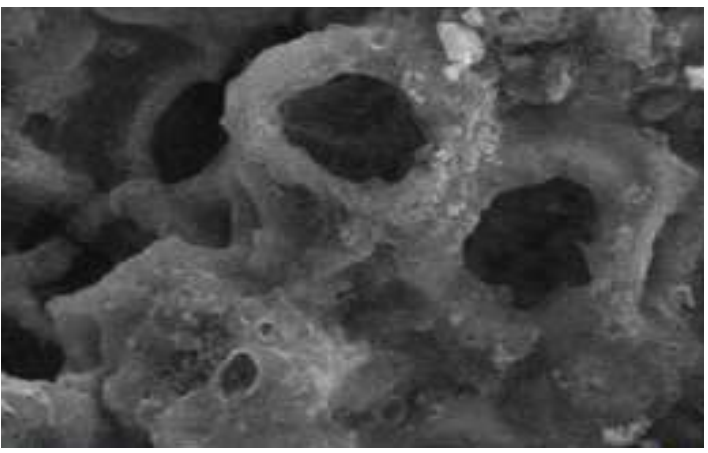

(d)

Figure 8. SEM for morphology structure: (a) PKSB at a magnification of $1.00 \mathrm{kX}$, (b) PKSB at a magnification of $2.00 \mathrm{kX}$, (c) PKSGAC at a magnification of $500 \mathrm{X}$, dan (d) PKSGAC at a magnification of $1.50 \mathrm{kX}$.

From Figure 8, it can be seen that there was a huge difference between the structures for both of the samples. Figure $8(\mathrm{a}, \mathrm{b})$ shows no porous image on the surface of the PKSB. This might be due to there being no activation treatment that had taken place on the PKSB. Figure 8 (c, d) shows a welldeveloped honeycomb-like structure porous surface. According to Ogungbenro et al. [27], the pore development during the activation process was important in order to enhance the surface area and pore volume of the $\mathrm{AC}$. 


\subsection{Application for colour removal}

The adsorption kinetics depended on the structural characteristic of the ACs surface, which included its surface area and pore volume. The removal of organic molecules by AC depended on the size of the organic compound [28]. MB had an area of $2.08 \mathrm{~nm}^{2}$ and only enter in large micropores and mesopores [29]. The removal of smaller molecules required larger micropore, while the removal of larger molecules prioritized the importance of both micropores and macropores. Table 4 shows the data for the application of color removal by using the MB. Before proceeding with the test, a calibration curve was prepared in order to find the coefficient correlation that was close to 1. In this study, the mass of PKSGAC, the contact time and the solution temperature were kept constant, having the value $0.2 \mathrm{~g}, 50 \mathrm{~min}$ and $60^{\circ} \mathrm{C}$, respectively.

Table 4. Percentage of concentration removed at different conditions of the PKSGAC

\begin{tabular}{|c|c|c|c|}
\hline \multirow{2}{*}{$\begin{array}{c}\text { MB concentration } \\
(\mathbf{m g} / \mathbf{l})\end{array}$} & \multicolumn{3}{|c|}{ Percentage of concentration removed (\%) } \\
\cline { 2 - 4 } & $\mathbf{8 5 0 - 5 0 - 2 . 5 *}$ & $\mathbf{7 0 0 - 1 0 0 - 0 . 4}^{*}$ & $\mathbf{7 7 5 - 7 5 - 0 . 4}^{*}$ \\
\hline 5 & 42.78 & 87.91 & 97.63 \\
\hline 10 & 38.90 & 86.47 & 90.46 \\
\hline 15 & 29.46 & 86.06 & 89.43 \\
\hline 20 & 28.06 & 85.48 & 89.61 \\
\hline
\end{tabular}

Notes: *The table header code represents activation temperature $\left({ }^{\circ} \mathrm{C}\right)$ - $\mathrm{KOH}$ concentration $(\% \mathrm{w} / \mathrm{v})$ - particle size $(\mathrm{mm})$. Example: activation temperature $=850^{\circ} \mathrm{C} ; \mathrm{KOH}$ concentration $=50 \% \mathrm{w} / \mathrm{v}$; particle size $=2.55 \mathrm{~mm}$ was represented by the code $850-50-2.5$.

Table 4 shows that at $5 \mathrm{mg} / \mathrm{l} \mathrm{MB}$ concentration, the amount of percentage removal of MB was high. However, as the concentration increased, the percentage of removal for both 700-100-0.4 and 77575-0.4 reduced slightly and continued to be constant. This might be due to the non-availability of vacant active sites and active functional groups on the surface of PKSGAC. At 50 min contact time, both of the samples had already reached its maximum adsorption capacity which were $86 \%$ and $90 \%$ respectively. For 850-50-2.5 PKSGAC sample, after $50 \mathrm{~min}$, the sample had achieved less than 45\% adsorption. This sample was treated to higher amount of $\mathrm{KOH}$ concentration which could have increased the amount of surface area and active sites to adsorb the MB. However, above a certain $\mathrm{KOH}$ concentration, the changes were lower [30]. This might be due to the higher formation of micropores space with increasing $\mathrm{KOH}$ concentration, therefore causing an increase of micropore to total surface area [31]. Higher $\mathrm{KOH}$ concentration might not be suitable for adsorption of larger molecules, as it was too big for the micropore. The size of PKSGAC particle could also affect the rate of adsorption. This was because smaller particles had faster penetration into available adsorption surface while bigger particle size would slow down the adsorption rate. Therefore, it could be that PKSGAC would require longer contact time before it could reach the adsorption equilibrium. Furthermore, an optimum combination of low $\mathrm{KOH}$ concentration and high activation temperature might improve the adsorption further. It was concluded that the particle size had a larger effect on the adsorption of PKSGAC compared to iodine number. 


\section{Conclusions}

Thermal analysis showed that the total weight loss of the PKSB sample was $58.30 \%$ and the range of the product yield for the PKSGAC from the 18 experiments suggested by RSM was in between $33.23 \%$ to $96.33 \%$. The PKSGAC bulk density between $0.17 \mathrm{~g} / \mathrm{cm}^{3}$ and $0.50 \mathrm{~g} / \mathrm{cm}^{3}$, the ash content value from $2 \%$ to $12 \%$, and moisture content range from $0 \%$ to $39 \%$. The highest iodine value was achieved $1320 \mathrm{mg} / \mathrm{g}$ at activation temperature of $850^{\circ} \mathrm{C}, \mathrm{KOH}$ concentration of $50 \% \mathrm{w} / \mathrm{v}$ and particle size of $0.4 \mathrm{~mm}$. From the RSM model, an iodine number of $1100 \mathrm{mg} / \mathrm{g}$ could be obtained using an activation temperature of $850{ }^{\circ} \mathrm{C}$, the $\mathrm{KOH}$ concentration of $69.22 \% \mathrm{w} / \mathrm{v}$ and the particle size of 0.59 $\mathrm{mm}$. The result also predicted $6.58 \%$ of moisture content, $7.25 \%$ of ash content, and $0.38 \mathrm{~g} / \mathrm{cm}^{3}$ for bulk density. BET analysis for PKSGAC sample prepared at $775^{\circ} \mathrm{C}$ activation temperature, $75 \% \mathrm{w} / \mathrm{v}$ $\mathrm{KOH}$ concentration and $0.4 \mathrm{~mm}$ particle, showed that the sample had $581 \mathrm{~m}^{2} / \mathrm{g}$ for $\mathrm{S}_{\mathrm{BET}}$ and 0.3173 $\mathrm{cm}^{3} / \mathrm{g}$ for the $\mathrm{V}_{\text {tot }}$ which was comparable to the iodine test value of $580.07 \mathrm{mg} / \mathrm{g}$.

\section{Acknowledgements}

The authors would like to express greatest appreciation to the Borneo Energy Sdn. Bhd., Malaysia for the material and financial support to this study.

\section{References}

[1] Carrier, M., Hugo, T., Gorgens, J., \& Knoetze, H. (2011). Comparison of slow and vacuum pyrolysis of sugar cane bagasse. Journal of Analytical and Applied Pyrolysis, 90(1), 18-26. https://doi.org/10.1016/j.jaap.2010.10.001

[2] De Cademartori, P. H. G., Mattos, B. D., Lourençon, T. V., Harres, A. N., Capobianco, G., Matos, M., Bolzon de M. G. I. \& Magalhaes, W. L. E. (2017). Production of activated carbon from fast pyrolysis biochar. In: International Symposium on Wood, Fibre and Pulping Chemistry, 19., Porto Seguro. Proceedings. Viçosa, MG: UFV, 229-232.

[3] Onundi, Y. B., Al-Mamun, A., Al-Khatib, M. A. F. R., \& Ahmed, Y. M. (2011). Growth of carbon nanomaterials on granular activated carbon. Advanced Materials Research, 264, 535-541. https://doi.org/10.4028/www.scientific.net/AMR.264-265.535

[4] Sun, K., Ro, K., Guo, M., Novak, J., Mashayekhi, H., \& Xing, B. (2011). Sorption of bisphenol A, $17 \alpha-$ ethinyl estradiol and phenanthrene on thermally and hydrothermally produced biochars. Bioresource Technology, 102(10), 5757-5763. https://doi.org/10.1016/j.biortech.2011.03.038

[5] Ahmed, M. B., Zhou, J. L., Ngo, H. H., Guo, W., \& Chen, M. (2016). Progress in the preparation and application of modified biochar for improved contaminant removal from water and wastewater. Bioresource Technology, 214, 836-851. https://doi.org/10.1016/j.biortech.2016.05.057

[6] Menya, E., Olupot, P. W., Storz, H., Lubwama, M., \& Kiros, Y. (2018). Production and performance of activated carbon from rice husks for removal of natural organic matter from water: a review. Chemical Engineering Research and Design, 129, 271-296. https://doi.org/10.1016/j.cherd.2017.11.008

[7] Bertone, E., Chang, C., Thiel, P., \& O’Halloran, K. (2018). Analysis and modelling of powdered activated carbon dosing for taste and odour removal. Water Research, 139, 321-328. https://doi.org/10.1016/j.watres.2018.04.023

[8] Santadkha, T., \& Skolpap, W. (2017). Economic comparative evaluation of combination of activated carbon generation and spent activated carbon regeneration plants. J. Eng. Sci. Technol, 12(12), 3329-3343. ISSN: $1823-4690$

[9] Rashidi, N. A., \& Yusup, S. (2019). Production of palm kernel shell-based activated carbon by direct physical activation for carbon dioxide adsorption. Environmental Science and Pollution Research, 26(33), 3373233746. https://doi.org/10.1007/s11356-018-1903-8

[10] Yuliusman, N. Afdhol, M. Amiliana, R. A., Hanafi, A. \& Rachmanda B. (2017). Preparation of activated carbon from palm shells using $\mathrm{KOH}$ and $\mathrm{ZnCl}_{2}$ as the activating agent. IOP Conference Series: Materials Science and Engineering 180 (1), 012282. doi:10.1088/1757-899X/180/1/012282

[11] Ridout, A. J., Carrier, M., Collard, F. X., \& Görgens, J. (2016). Energy conversion assessment of vacuum, slow and fast pyrolysis processes for low and high ash paper waste sludge. Energy Conversion and

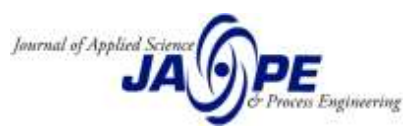


Management, 111, 103-114. https://doi.org/10.1016/j.enconman.2015.12.043.

[12] Al Arni, S. (2018). Comparison of slow and fast pyrolysis for converting biomass into fuel. Renewable Energy, 124, 197-201.https://doi.org/10.1016/j.renene.2017.04.060

[13] Azargohar, R., \& Dalai, A. K. (2006). Biochar as a precursor of activated carbon. In Twenty-seventh Symposium on Biotechnology for Fuels andCchemicals, Humana Press, 762-773. https://doi.org/10.1007/978-1-59745-268-7_62

[14] Behera, S. K., Meena, H., Chakraborty, S., \& Meikap, B. C. (2018). Application of response surface methodology (RSM) for optimization of leaching parameters for ash reduction from low-grade coal. International Journal of Mining Science and Technology, 28(4), 621-629. https://doi.org/10.1016/j.ijmst.2018.04.014.

[15] Bono, A., Krishnaiah, D., \& Rajin, M. (2008). Products and process optimization using response surface methodology. Universiti Malaysia Sabah. ISBN 978-983-2369-8

[16] Azmi, N. B., Bashir, M. J., Sethupathi, S., Wei, L. J., \& Aun, N. C. (2015). Stabilized landfill leachate treatment by sugarcane bagasse derived activated carbon for removal of color, COD and NH3-Noptimization of preparation conditions by RSM. Journal of Environmental Chemical Engineering, 3(2), 1287-1294. https://doi.org/10.1016/j.jece.2014.12.002

[17] Andas, J., Rahman, M. L. A., \& Yahya, M. S. M. (2017). Preparation and characterization of activated carbon from palm kernel shell. IOP Conference Series: Materials Science and Engineering, 226(1), 1-7. doi:10.1088/1757-899X/226/1/012156

[18] Abechi, S. E., Gimba, C. E., Uzairu, A., Kagbu, J. A., \& Ocholi, O. J. (2013). Equilibrium adsorption studies of methylene blue onto palm kernel shell-based activated carbon. International Refereed Journal of Engineering and Science, 2(5), 38-45. ISSN (Online) 2319-183X

[19] Alias, N. B., Ibrahim, N., Hamid, M. K. A., Hasbullah, H., Ali, R. R., \& Kasmani, R. M. (2015). Investigation of oil palm wastes' pyrolysis by thermo-gravimetric analyzer for potential biofuel production. Energy Procedia, 75, 78-83. https://doi.org/10.1016/j.egypro.2015.07.141

[20] Adinata, D., Daud, W. M. A. W., \& Aroua, M. K. (2007). Preparation and characterization of activated carbon from palm shell by chemical activation with $\mathrm{K}_{2} \mathrm{CO}_{3}$. Bioresource Technology, 98(1), 145-149. https://doi.org/10.1016/j.biortech.2005.11.006

[21] Ekpete, O. A., \& Horsfall, M. J. N. R. (2011). Preparation and characterization of activated carbon derived from fluted pumpkin stem waste (Telfairia occidentalis Hook F). Res J Chem Sci, 1(3), 10-17. ISSN 2231$606 \mathrm{X}$

[22] Anisuzzaman, S. M., Joseph, C. G., Daud, W. M. A. B. W., Krishnaiah, D., \& Yee, H. S. (2015). Preparation and characterization of activated carbon from Typha orientalis leaves. International Journal of Industrial Chemistry, 6(1), 9-21. https://doi.org/10.1007/s40090-014-0027-3.

[23] Alzorqi, I., Ketabchi, M. R., Sudheer, S., \& Manickam, S. (2016). Optimization of ultrasound induced emulsification on the formulation of palm-olein based nanoemulsions for the incorporation of antioxidant $\beta$ d-glucan polysaccharides. Ultrasonics Sonochemistry, https://doi.org/10.1016/j.ultsonch.2015.12.004

[24] Hassen, J. H. (2017). Effect of KOH ratio on the formation of activated carbon from pressed wood residues. Int J Pharm Sci Res, 8, 4875-4880. E-ISSN: 0975-8232

[25] Fu, Y., Shen, Y., Zhang, Z., Ge, X., \& Chen, M. (2019). Activated bio-chars derived from rice husk via oneand two-step KOH-catalyzed pyrolysis for phenol adsorption. Science of the Total Environment, 646, 15671577. https://doi.org/10.1016/j.scitotenv.2018.07.423

[26] Esfandiari, A., Kaghazchi, T., \& Soleimani, M. (2012). Preparation and evaluation of activated carbons obtained by physical activation of polyethyleneterephthalate (PET) wastes. Journal of the Taiwan Institute of Chemical Engineers, 43(4), 631-637. https://doi.org/10.1016/j.jtice.2012.02.002

[27] Ogungbenro, A. E., Quang, D. V., Al-Ali, K. A., Vega, L. F., \& Abu-Zahra, M. R. (2018). Physical synthesis and characterization of activated carbon from date seeds for $\mathrm{CO}_{2}$ capture. Journal of Environmental Chemical Engineering, 6(4), 4245-4252. https://doi.org/10.1016/j.jece.2018.06.030.

[28] Valderrama, C., Cortina, J. L., Farran, A., Gamisans, X., \& Lao, C. (2007). Kinetics of sorption of polyaromatic hydrocarbons onto granular activated carbon and Macronet hyper-cross-linked polymers (MN200). Journal of Colloid and Interface Science, 310(1), 35-46. https://doi.org/10.1016/j.jcis.2007.01.039

[29] Nunes, C. A., \& Guerreiro, M. C. (2011). Estimation of surface area and pore volume of activated carbons by methylene blue and iodine numbers. Química Nova, 34, 472-476. https://doi.org/10.1590/S010040422011000300020

[30] Geçgel, Ü., Özcan, G., \& Gürpınar, G. Ç. (2013). Removal of methylene blue from aqueous solution by 
activated carbon prepared from pea shells (Pisum sativum). Journal of Chemistry, 1-9. https://doi.org/10.1155/2013/614083

[31] Yasin, Y., Hussein, M. Z., \& Ahmad, F. H. (2007). Adsorption of methylene blue onto treated activated carbon. Malaysian Journal of Analytical Sciences, 11(2), 400-406. ISSN 1394-2506 